\title{
Final adult height of children with idiopathic short stature: a multicenter study on GH therapy alone started during peri- puberty
}

Di Wu', Rui-min Chen², Shao-ke Chen ${ }^{3}$, Ge-li Liư ${ }^{4}$ Lin-qi Chen ${ }^{5}$, Yu Yang ${ }^{6}$, Xin-li Wang ${ }^{7}$, Ya-guang Peng ${ }^{8}$ and Chun-xiu Gong ${ }^{1 *}$

\begin{abstract}
Background: To evaluate the efficacy of GH in improving FAH in ISS children in a multicenter study.

Methods: A real-world observation was carried out. Children with ISS in seven hospitals in China were enrolled. The height gains standard deviation score and the height gain over the target height were evaluated.

Results: There were 344 ISS patients (217 boys and 127 girls). The baseline average age of boys and girls was 12.7 and 11.7 years, with bone age of 11.7 and 10.1 years, respectively. The baseline height SDS of boys and girls was 3.07 and -2.74 , and the FAH SDS was -1.91 and -1.38 , respectively. Compared with the baseline height SDS, the FAH SDS was significantly increased in both boys and girls (both $P=0.0000$ ). The FAH SDS was the highest (gain by 1.54 SD) in the $\geq 2 y$ treatment course group. Two hundred eighteen patients $(218 / 344,63.4 \%)$ had a FAH SDS $>-2$ SD. Among these patients, girls in the 1-2y treatment course group and $\geq 2 y$ group had a FAH SDS higher than TH SDS. Even in the control group, a spontaneous catch-up growth of 1.16 SD was observed. A multivariate linear regression model was used to analyze the results, with FAH SDS as the dependent variable. It was found that the treatment course and baseline height SDS in the boys' model were statistically significant $(P<0.05)$, whereas the baseline height SDS and baseline bone age significantly affected the girls' FAH SDS $(P<0.05)$.
\end{abstract}

Conclusions: Both girls and boys of ISS improved FAH by GH therapy even if treatments begin over 10 years old and majority of them reached TH. Some peri-puberty ISS will have a spontaneous height gain. We recommend the course of GH treatment more than 2 years for girls, and longer courses for boys.

Keywords: Final adult height (FAH), Idiopathic short stature (ISS), Standard deviation score (SDS), Baseline height, Target height (TH)

\footnotetext{
* Correspondence: chunxiugong@sina.com

'Department of Endocrine and Genetics and Metabolism, Beijing Children's Hospital, Capital Medical University, National Centre for Children's Health, No. 56 Nanlishi Road, Xicheng District, Beijing 100045, China

Full list of author information is available at the end of the article
}

C The Author(s). 2020 Open Access This article is licensed under a Creative Commons Attribution 4.0 International License, which permits use, sharing, adaptation, distribution and reproduction in any medium or format, as long as you give appropriate credit to the original author(s) and the source, provide a link to the Creative Commons licence, and indicate if changes were made. The images or other third party material in this article are included in the article's Creative Commons licence, unless indicated otherwise in a credit line to the material. If material is not included in the article's Creative Commons licence and your intended use is not permitted by statutory regulation or exceeds the permitted use, you will need to obtain permission directly from the copyright holder. To view a copy of this licence, visit http://creativecommons.org/licenses/by/4.0/. The Creative Commons Public Domain Dedication waiver (http://creativecommons.org/publicdomain/zero/1.0/) applies to the data made available in this article, unless otherwise stated in a credit line to the data. 


\section{Background}

Idiopathic short status (ISS) is defined as a condition in which the height of an individual is more than 2SD score (SDS) below the corresponding mean height for a given age, sex, and population group without evidence of systemic, endocrine, nutritional, or chromosomal abnormalities. Children with ISS have normal birth weight and are GH sufficient [1]. The incidence of ISS (including constitutional delay of growth and puberty and familial short stature) is about 23 in 1000 [1-3]. In 2003, the US Food and Drug Administration approved growth hormone $(\mathrm{GH})$ for the treatment of ISS patients (height $<-2.25 \mathrm{SD}$ ). The main purpose of $\mathrm{GH}$ therapy for ISS is to attain normal adult height and avoid daily life inconvenience and psychological problems caused by extreme or unacceptable short stature. However, few clinical studies have explored whether the final adult height $(\mathrm{FAH})$ can reach the normal range after $\mathrm{GH}$ therapy. FAH is considered the golden indicator for evaluating the efficacy of $\mathrm{GH}$ therapy $[4,5]$. However, the predicted FAH following a short period of treatment is dynamic and cannot reflect the actual FAH. Owing to the heterogeneity of the treated ISS populations and the individualization of treatment, only a few randomized trials with small sample sizes have observed ISS until FAH [6-10]. A randomized study of FAH typically takes 8 years or more to complete and is often difficult to implement in clinical settings. Thus, most of the currently available studies only have small samples and are carried out in a single center. More studies are needed to confirm the efficacy of GH in the treatment of ISS.

In the clinical real world, many ISS children's parents are willing to observe their children growth when they are young. As children grow older and become peri-puberty, more people come to see doctors. What is the effect of $\mathrm{GH}$ treatment alone in peripuberty? Past literatures are not accurate. This is the first multicenter study in China on the efficacy of growth hormone alone in the treatment of elder children. In our current study, we followed up children with ISS diagnosed by the departments of pediatric endocrinology in seven tertiary hospitals in different regions of mainland China, and evaluated the efficacy of $\mathrm{GH}$ for ISS children until FAH.

\section{Methods}

\section{Subjects}

Patients with ISS confirmed in the departments of pediatric endocrinology in seven tertiary hospitals, namely Beijing Children's Hospital Affiliated to Capital Medical University, Fuzhou Children's Hospital of Fujian Medical University Teaching Hospital, The second Affiliated Hospital of Guangxi Medical University, General Hospital of Tianjin Medical University, Children's
Hospital of Soochow University, Children's Hospital of Jiangxi Province, and Third Hospital of Peking University, were enrolled in this study.

The inclusion criteria included: (a) body height less than -2 SD of the height in the general population with the same race, age, sex, and other factors; (b) without systemic disease, endocrine disease, nutritional disease, or chromosomal abnormality; (c) with normal body length and weight at birth; (d) with a serum peak GH concentration $>7 \mathrm{ng} / \mathrm{mL}$ at peak $\mathrm{GH}$ stimulation test and normal insulin-like growth factor 1; (e) born before January 1, 2001; (f) had been treated with GH alone for ISS but the GH therapy had been withdrawn and FAH reached, regardless of whether the patient was in Tanner stage 1 at admission; and ( $g$ ) informed consent was signed by parents and children older than 8 years.

The exclusion criteria included: (a) children who were treated with $\mathrm{GnRHa}$ (gonadotropin-releasing hormone agonist); and (b) obese children.

Regarding the concept of peri-puberty, there is no well-recognized age limit for its definition. Since the baseline Tanner stages differed in our research populations, the term peri-puberty was used in our study.

All patients and their parents signed informed consent for data collection.

\section{Methods}

A real-world observation was carried out. Clinical data including name, sex, date of birth, age at baseline, baseline height, baseline bone age based on Greulich-Pyle methodology, GH treatment course, age at last followup, FAH, and parents' heights were recorded. The baseline height SD score (SDS), FAH SDS, and target height (TH) SDS were calculated. GH was subcutaneously injected at a dose of $0.15-0.2 \mathrm{IU} / \mathrm{kg} /$ day.

The height SD score (HtSDS) was calculated by referring to the 2005 Standard Deviations of Height and Weight for Children and Adolescents Aged 0-18 years in China [11].

Height standard deviation score $(\mathrm{HtSDS})=($ actual height - average height for children of the same sex and age $) \div$ (SD of the heights for children of the same sex and age) [11].

TH (i.e., mid-parental target height) was as follows:

$$
\begin{aligned}
& \text { Boys'TH }(\mathrm{cm})=(\text { father's height }+ \text { mother's height }+13) \div 2 \\
& \text { Girls'TH }(\mathrm{cm})=(\text { father's height }+ \text { mother's height }-13) \div 2^{(12)}
\end{aligned}
$$

FAH was defined as follows: age at the last follow-up was $>15$ years, height velocity was below $1 \mathrm{~cm} /$ year, and the GH therapy had been discontinued [12].

The primary endpoint was the difference between FAH SDS and baseline height SDS, i.e., the height SDS gain, expressed as $\triangle 1 \mathrm{HtSDS}$. The secondary endpoint 
was the difference between FAH SDS and TH SDS, i.e., the height gain over the TH $(\triangle 2 \mathrm{HtSDS}) . \triangle 3 \mathrm{HtSDS}$ is baseline height SDS minus TH SDS. In addition, influencing factors of height SDS were analyzed.

The control group comprised patients who had been treated for less than 3 months. The remaining patients were divided into the 3-6 $\mathrm{m}$ group (treated for 3-6 months), 6-12 m group (treated for 6 months to 1 year), $1-2 y$ group (treated for $1-2$ years), and $\geq 2 y$ group (treated for 2 or more years).

Patients were also stratified according to gender.

Screening flowchart:

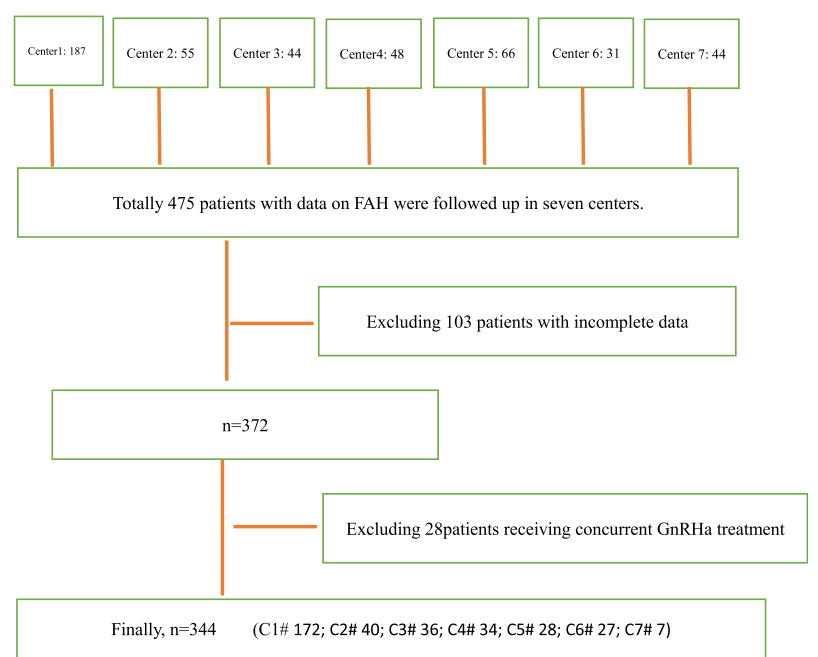

\section{Statistical analysis}

Statistical analysis was performed using SPSS 20.0 software. A normal distribution test showed that all measurement data were normally distributed. Data are presented as mean $\pm \mathrm{SD}$. The means of two independent samples were compared by using the $t$ test, and the comparisons of means among multiple groups were based on analysis of variance. The influencing factors of FAH SDS were analyzed by multivariate linear regression. A $P$ value of less than 0.05 was considered significantly different.

\section{Results}

\section{General data}

Among the 344 ISS patients in seven centers, there were 217 boys and 127 girls. The average age of boys and girls when starting the treatment (baseline) was $12.7 \pm 1.87$ and $11.7 \pm 1.61$ years, with bone age of $11.7 \pm 2.32$ years and $10.1 \pm 2.03$ years, respectively. The growth stopped at the final follow-up visit, with a mean age of $18.5 \pm$ 2.25 years for boys and $18.0 \pm 2.02$ years for girls (Table 1).

The baseline height SDS of boys and girls was -3.07 and -2.74 , and the FAH SDS was -1.91 and -1.38 , respectively. Compared with the baseline height SDS, the FAH SDS was significantly increased in both boys and girls (both $P=0.0000$ ) (Table 1).

Comparisons between FAH SDS and baseline height SDS According to the treatment course, patients who had been treated for less than 3 months were designated the control group, and the remaining patients were divided into the 3-6 m, 6-12 m, 1-2y, and $\geq 2 y$ groups. The average course of treatment was 2.92 years in the $\geq 2 y$ group.

Table 1 General data

\begin{tabular}{|c|c|c|c|c|}
\hline & Boys & Girls & $\mathrm{t}$ & $P$ \\
\hline Baseline age (years) & $12.7 \pm 1.87$ & $11.7 \pm 1.61$ & 4.741 & $0.000^{*}$ \\
\hline Baseline bone age (years) & $11.73 \pm 2.32$ & $10.08 \pm 2.03$ & -1.379 & 0.169 \\
\hline Treatment course (years) & $1.33 \pm 1.296(0.06-8.33)$ & $1.33 \pm 1.159(0.08-5.65)$ & -0.046 & 0.963 \\
\hline Age at the final follow-up (years) & $18.5 \pm 2.25$ & $18.0 \pm 2.02$ & 1.951 & 0.052 \\
\hline Baseline body height SDS & $-3.07 \pm 1.054$ & $-2.74 \pm 0.761$ & -3.311 & $0.001^{*}$ \\
\hline $\mathrm{FAH}(\mathrm{cm})$ & $160.6 \pm 8.09$ & $153.0 \pm 5.46$ & 10.404 & $0.000^{*}$ \\
\hline FAH SDS & $-1.91 \pm 1.284$ & $-1.38 \pm 1.017$ & -4.264 & $0.000^{*}$ \\
\hline TH (Median height of parents $(\mathrm{cm})$ & $167.7 \pm 4.51$ & $155.6 \pm 4.12$ & 23.354 & $0.000^{*}$ \\
\hline TH SDS & $-0.83 \pm 0.747$ & $-0.98 \pm 0.766$ & 1.651 & 0.100 \\
\hline$\triangle 1$ (FAH SDS - baseline height SDS) & $1.15 \pm 1.387$ & $1.49 \pm 0.955$ & -2.605 & $0.010^{*}$ \\
\hline$\triangle 2(F A H ~ S D S-T H S D S)$ & $-1.10 \pm 1.403$ & $-0.27 \pm 1.271$ & -5.215 & $0.000^{*}$ \\
\hline$\Delta 3$ (baseline height SDS - TH SDS) & $-2.22 \pm 1.291$ & $-1.74 \pm 0.931$ & -3.413 & $0.001^{*}$ \\
\hline Comparisons between FAH SDS and baseline height SDS & $\begin{array}{l}P=0.000^{*} \\
t=10.245\end{array}$ & $\begin{array}{l}P=0.000^{*} \\
t=11.880\end{array}$ & & \\
\hline
\end{tabular}


The baseline height SDS and TH SDS were comparable among the five groups.

The baseline ages of the control group, 3-6 m group, and $6-12 \mathrm{~m}$ group were significantly larger than that of the $\geq 2 y$ group.

The height gain SDS (i.e., between FAH SDS and baseline height SDS $\left[{ }^{1} \mathrm{HtSDS}\right]$ ) was $1.16,1.30,1.00,1.01$, and 1.54 in each group; compared with the control group, the $P$ value was $0.503,0.492,0.525$, and 0.082 , showing no significant difference. However, the FAH SDS was highest (increased by 1.54 SD) in the $\geq 2 y$ group. The $\triangle 1 \mathrm{HtSDS}$ showed a gradually increasing trend in the $6-12 \mathrm{~m}$ group, $1-2 \mathrm{y}$ group, and $\geq 2 \mathrm{y}$ group. Compared with the other two groups, the $\geq 2 y$ group had significantly different $\triangle 1 \mathrm{HtSDS}(P=0.022)$. Even in the control group (regarded as an untreated group), a spontaneous catch-up growth of 1.16 SD was observed. However, the absolute height gain $(\Delta \mathrm{H}$ tSDS $)$ was clinically significantly higher in $\geq 2 y$ group than in the control group (1.54 versus 1.16). In each group, there was significant difference between $\triangle 2 \mathrm{HtSDS}$ and $\triangle 3 \mathrm{HtSDS}$. (Table 2; Fig. 1 and Supp. Figure 1).

\section{Comparisons of FAH SDS and TH SDS}

According to the Chinese Children Growth Standards, an SDS value of 1 is considered a clinically acceptable boundary value with practical clinical significance. Based on the gender stratification, the difference between FAH SDS and TH SDS was compared. The FAH SDS (1.913) was 1.079 lower than the TH SDS $(-0.834)(95 \%$ confidence interval $[\mathrm{CI}]:-1.279$ to $-0.878, P>0.05)$ in boys and 0.398 lower $(95 \% \mathrm{CI}:-0.625$ to $-0.170, P<$ 0.001 ) in girls. Thus, the FAH SDS was closer to the TH SDS in girls after treatment.

\section{Analysis of patients with $\mathrm{FAH}$ attaining normal height} In total, 218 patients $(218 / 344,63.4 \%)$ had a FAH SDS > - $2 \mathrm{SD}$, attaining the normal and non-short height (Table 3), comprising 118 boys $(118 / 217,54.4 \%)$ and 100 girls (100/127, 78.7\%). Among these patients, girls in the 1 - $2 y$ group and $\geq 2 y$ group had a FAH SDS higher than $\mathrm{TH}$ SDS. FAH SDS was lower than TH SDS in all groups of boys who attained the normal and non-short height (Table 3 and Supp. Figure 2).

Compared with the pooled group with a FAH attaining the normal height, 8 of 10 girls and 11 of 31 boys in the control group attained the normal adult height. There was statistical significance between the number of boys in the control group and that in the pooled group $(P=$ $0.049)$; that is, the number of boys in the control group attaining the normal height was smaller than that of boys in the pooled group reaching the normal height, while there was no significant difference between the control group and the pooled group.

\section{Analysis of influencing factors of $\mathrm{FAH}$}

A multivariate linear regression model was used to analyze the results, with FAH SDS as the dependent variable and the baseline age, baseline bone age, baseline height SDS, treatment course, and $\mathrm{TH}$ as independent variables. It was found that treatment course and baseline height SDS in the boys' model were statistically significant $(P<0.05)$, whereas the baseline height SDS and baseline bone age affected the girls' FAH SDS (Table 4).

\section{Discussion}

This is the first observational multicenter study with FAH results in China on the efficacy of growth hormone alone for ISS. It was an observational study based on the

Table 2 Comparisons of baseline height SDS, FAH SDS, and TH SDS

\begin{tabular}{|c|c|c|c|c|c|c|c|c|c|}
\hline $\begin{array}{l}\text { Treatment } \\
\text { course }\end{array}$ & $\mathrm{n}$ & $\begin{array}{l}\text { Baseline } \\
\text { age (y) }\end{array}$ & $\begin{array}{l}\text { Baseline } \\
\text { height SDS }\end{array}$ & $\begin{array}{l}\text { FAH } \\
\text { SDS }\end{array}$ & $\begin{array}{l}\text { TH } \\
\text { SDS }\end{array}$ & $\begin{array}{l}\triangle 1 \mathrm{HtSDS}=\mathrm{FAH} \text { SDS - } \\
\text { baseline height SDS }\end{array}$ & $\begin{array}{l}\triangle 2 \mathrm{HtSDS}=\mathrm{FAH} \\
\mathrm{SDS}-\mathrm{TH} \text { SDS }\end{array}$ & $\begin{array}{l}\triangle 3 \mathrm{HtSDS}= \\
\text { baseline } \\
\text { height SDS - } \\
\text { TH SDS }\end{array}$ & $\begin{array}{l}\text { Within different } \\
\text { treatment courses } \\
\text { Comparison } \\
\text { between } \\
\Delta 2 \text { and } \Delta 3\end{array}$ \\
\hline $\begin{array}{l}3 \mathrm{~m} \\
\text { Control }\end{array}$ & 41 & $12.9 \pm 1.75$ & $-3.14 \pm 0.723$ & $-1.98 \pm 1.065$ & $-0.95 \pm 0.749$ & $1.16 \pm 1.036$ & $-0.98 \pm 1.106$ & $\begin{array}{l}-2.22 \pm \\
1.030\end{array}$ & $\begin{array}{l}t=4.927 \\
P=0.000^{*}\end{array}$ \\
\hline $3-6 m$ & 70 & $12.7 \pm 1.76$ & $-2.99 \pm 0.904$ & $-1.68 \pm 1.035$ & $-0.96 \pm 0.720$ & $\begin{array}{l}1.30 \pm 1.090 \\
\mathrm{t}=-0.673 P=0.503\end{array}$ & $-0.78 \pm 1.171$ & $\begin{array}{l}-1.99 \pm \\
0.997\end{array}$ & $\begin{array}{l}t=6.044 \\
P=0.000^{*}\end{array}$ \\
\hline $6-12 m$ & 55 & $12.5 \pm 1.86$ & $-2.87 \pm 0.838$ & $-1.88 \pm 1.196$ & $-0.99 \pm 0.739$ & $\begin{array}{l}1.00 \pm 1.273 \\
t=0.690 P=0.492\end{array}$ & $-0.94 \pm 1.293$ & $\begin{array}{l}-1.89 \pm \\
0.900\end{array}$ & $\begin{array}{l}t=4.351 \\
P=0.000^{*}\end{array}$ \\
\hline $1-2 y$ & 81 & $12.3 \pm 1.75$ & $-2.79 \pm 0.775$ & $-1.76 \pm 1.417$ & $-0.93 \pm 0.758$ & $\begin{array}{l}1.01 \pm 1.312 \\
t=0.637 P=0.525\end{array}$ & $-0.84 \pm 1.483$ & $\begin{array}{l}-1.88 \pm \\
1.088\end{array}$ & $\begin{array}{l}t=4.920 \\
P=0.000^{*}\end{array}$ \\
\hline$\geq 2 y$ & 97 & $11.9 \pm 1.89$ & $-3.03 \pm 1.268$ & $-1.49 \pm 1.225$ & $-0.72 \pm 0.778$ & $\begin{array}{l}1.54 \pm 1.229 \\
\mathrm{t}=-1.751 P=0.082\end{array}$ & $-0.77 \pm 1.475$ & $\begin{array}{l}-2.25 \pm \\
1.560\end{array}$ & $\begin{array}{l}t=6.441 \\
P=0.000^{*}\end{array}$ \\
\hline \multirow[t]{2}{*}{ Total } & 344 & & $-2.96 \pm 0.968$ & $-1.72 \pm 1.219$ & $-0.89 \pm 0.756$ & $1.23 \pm 1.222$ & $-0.85 \pm 1.349$ & $\begin{array}{l}-2.05 \pm \\
1.194\end{array}$ & $\begin{array}{l}\mathrm{t}=11.764 \\
P=0.000^{*}\end{array}$ \\
\hline & & $\begin{array}{l}\mathrm{F}=3.693 \\
P=0.006^{*}\end{array}$ & $\begin{array}{l}F=1.226 \\
P=0.299\end{array}$ & $\begin{array}{l}F=1.581 \\
P=0.179\end{array}$ & $\begin{array}{l}F=1.608 \\
P=0.172\end{array}$ & $\begin{array}{l}F=2.910 \\
P=0.022^{*}\end{array}$ & $\begin{array}{l}F=0.261 \\
P=0.903\end{array}$ & $\begin{array}{l}F=1.500 \\
P=0.202\end{array}$ & \\
\hline
\end{tabular}




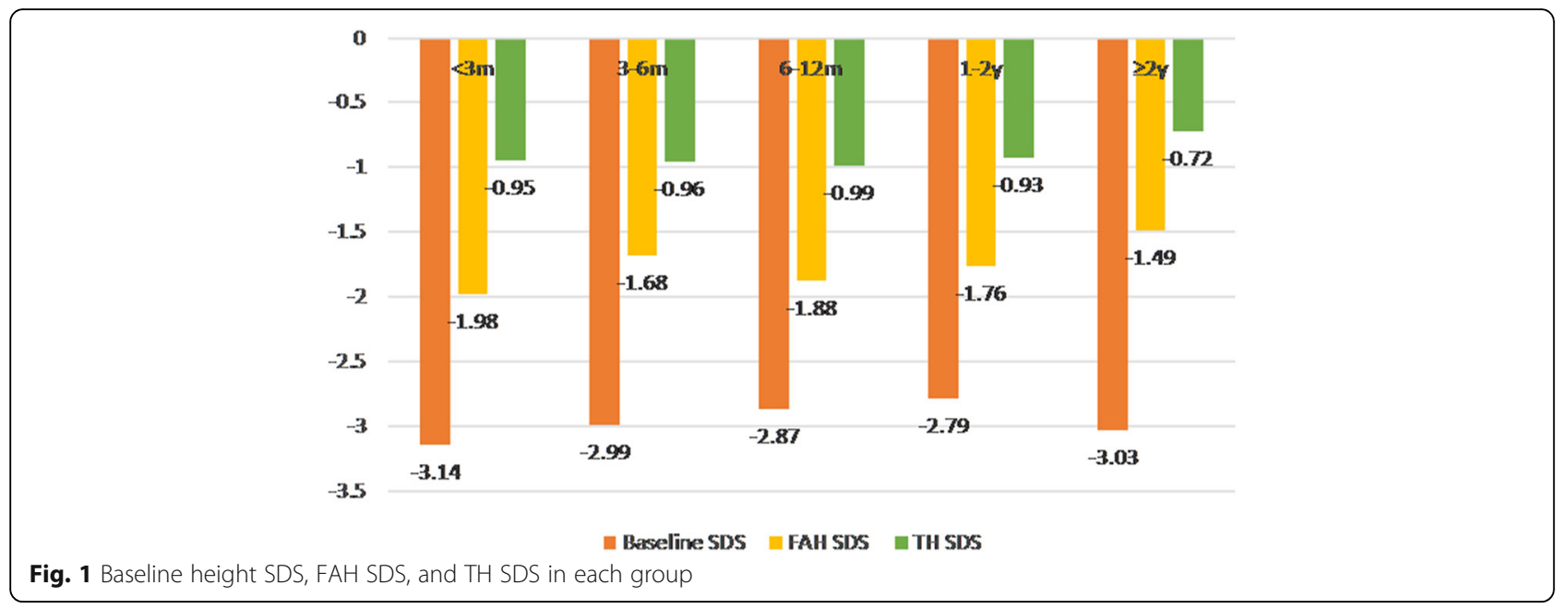

clinical reality and reflected the real-world situation. In addition to the follow-up of FAH, the difference between FAH SDS and baseline height SDS and between FAH height SDS and TH SDS was also evaluated. It was found that a treatment course of 2 years or more had better efficacy. Even for over 10 years old ISS children, GH therapy could improve FAH if the treatment course was long enough.

Randomized controlled trials (RCTs) have been recognized as high-quality research evidence because of their rigorous grouping/screening criteria and standardized treatment. However, sometimes RCTs do not actually reflect the clinical reality because the efficacy of GH for ISS varies greatly and the GH treatment is highly individualized in the true clinical setting. Although realworld retrospective studies are feasible, their data are limited by the natural characteristics of the treated children. In the study of short stature, it is difficult to find a control group without treatment: in clinical practice, few children will adhere to the follow-up protocol if no GH treatment is applied. In the current study, patients who had received GH treatment for less than 3 months were included in the control group, which was based on the following consideration: although $\mathrm{GH}$ is effective for a patient, such efficacy within a short period (3 months) can be neglected for the FAH; thus, the result of a short treatment course of up to 3 months is similar to that of natural growth. Our data comprised real-world clinical data, which may be used as evidence for long-term treatment of GH for ISS.

As known, the efficacy of GH in the treatment of ISS remains controversial. In a variety of prospective/retrospective, randomized/non-randomized, and controlled/ non-controlled trials, some researchers concluded that GH treatment improved ISS while others considered it ineffective. The efficacies in these studies varied dramatically [12-18]. Some meta-analyses showed that GHtreated ISS patients might gain more FAH than untreated children, but were still shorter than the normal populations. In the meta-analysis performed by Deodati and Canfarani, three RCTs that followed the ISS patients until FAH were included, among which the average treatment course was 4.6-6.2 years [8]. In these three RCTs the treated group gained 0.79 SDS $(4.7 \mathrm{~cm})$ more height than the control group without GH treatment. In the largest trial, the height attainment was 0.8 SDS (5 $\mathrm{cm}$ ) more in the treatment group than in the control group. In the study by Sotos and Tokar, the height attainment was 1.9 SDS in the treatment group and only 0.49 SDS in the untreated control group [3]. Wit et al. evaluated 239 children treated with $\mathrm{GH}$, of whom only 50 were followed up until FAH. The FAH increased by 1.52-1.85 SDS compared with baseline height [10]. In our current study, the FAH of boys and girls increased

Table 3 Comparisons of FAH SDS and TH SDS in the pooled group with FAH SDS > -2 SD

\begin{tabular}{|c|c|c|c|c|c|c|c|c|c|c|c|c|c|c|c|}
\hline \multirow{2}{*}{$\begin{array}{l}\text { Treatment } \\
\text { course }\end{array}$} & \multicolumn{5}{|c|}{ Total } & \multicolumn{5}{|l|}{ Girl } & \multicolumn{5}{|c|}{ Boy } \\
\hline & $n$ & FAH SDS & TH SDS & $t$ & $P$ & $n$ & FAH SDS & TH SDS & $\mathrm{t}$ & $P$ & $n$ & FAH SDS & TH SDS & $\mathrm{t}$ & $P$ \\
\hline$<3 m$ & 19 & $-1.17 \pm 0.741$ & $-0.70 \pm 0.585$ & -2.055 & 0.048 & 8 & $-0.81 \pm 0.971$ & $-0.86 \pm 0.656$ & 0.118 & 0.908 & 11 & $-1.42 \pm 0.429$ & $-0.57 \pm 0.525$ & -3.244 & $\overline{0.012}$ \\
\hline $3-6 m$ & 51 & $-1.20 \pm 0.632$ & $-0.93 \pm 0.638$ & -1.988 & 0.050 & 21 & $-1.38 \pm 0.543$ & $-1.05 \pm 0.815$ & -1.471 & 0.150 & 30 & $-1.09 \pm 0.612$ & $-0.86 \pm 0.516$ & -1.649 & 0.112 \\
\hline $6-12 m$ & 31 & $-1.03 \pm 0.676$ & $-0.96 \pm 0.859$ & -0.338 & 0.737 & 17 & $-1.01 \pm 0.793$ & $-0.97 \pm 0.620$ & -0.144 & 0.886 & 14 & $-1.03 \pm 0.547$ & $-0.95 \pm 1.100$ & -0.277 & 0.786 \\
\hline $1-2 y$ & 52 & $-0.88 \pm 0.706$ & $-0.88 \pm 0.630$ & -0.028 & 0.978 & 26 & $-0.99 \pm 0.704$ & $-1.08 \pm 0.606$ & 0.494 & 0.623 & 26 & $-0.83 \pm 0.707$ & $-0.66 \pm 0.590$ & -0.945 & 0.355 \\
\hline$\geq 2 y$ & 65 & $-0.76 \pm 0.641$ & $-0.71 \pm 0.798$ & -0.382 & 0.703 & 28 & $-0.61 \pm 0.550$ & $-0.77 \pm 0.917$ & 0.744 & 0.461 & 37 & $-0.88 \pm 0.713$ & $-0.67 \pm 0.709$ & -1.036 & 0.308 \\
\hline
\end{tabular}


Table 4 Analysis of influencing factors of FAH SDS

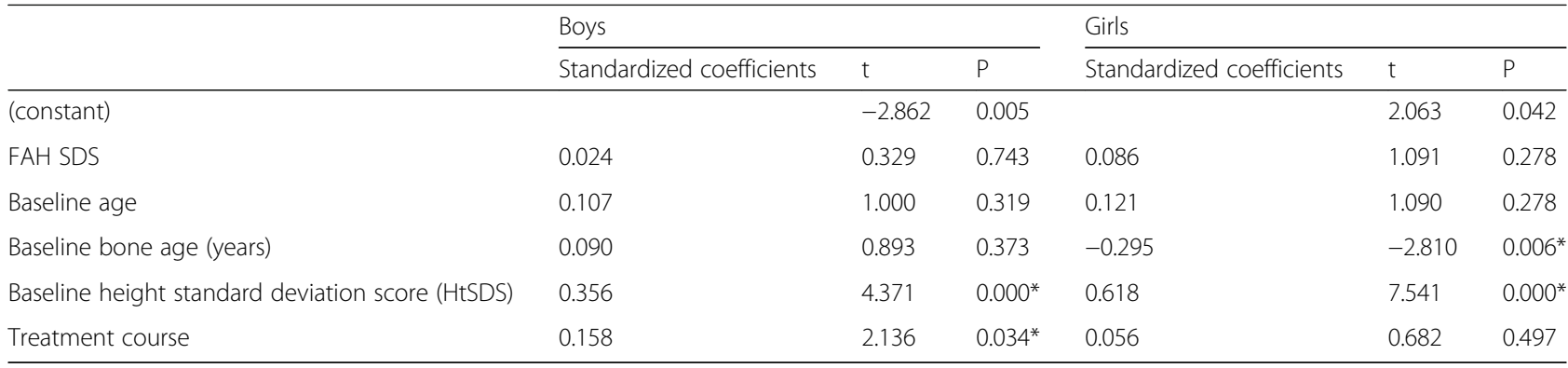

by 1.16 SD and 1.36 SD compared with baseline height, which is basically consistent with results reported in the literature. Compared with the $6 \mathrm{~m}-2 \mathrm{y}$ group, the $\geq 2 \mathrm{y}$ group had significantly more FAH gain over the baseline height. Therefore, GH treatment for more than 2 years can achieve better efficacy in ISS patients.

Our study showed that $54.4 \%$ of boys and $78.7 \%$ of girls had a FAH SDS $>-2$ SD after $\mathrm{GH}$ treatment. This result explains that $\mathrm{GH}$ therapy is effective even in peripuberty children. Among the girls who had been treated with $\mathrm{GH}>2$ years, their FAH was higher than $\mathrm{TH}$. This further confirmed that GH therapy could improve FAH and longer the better. For boys, FAH SDS was lower than TH SDS in all groups although they attained the normal height. It may be that boys need to improve their height longer than girls. In the GeNeSIS observation study by Pfäffle and colleagues, including United States, Germany and France data, shows that most children achieved near adult height (NAH) within the normal range (height $\mathrm{SDS}>-2$ ) after $\mathrm{GH}$ treatment [19]. The main population of our study is Chinese Han children. It shows that the same results as in Europe and America, the efficacy of growth hormone is similar.

The average age of boys and girls at baseline was $12.7 \pm$ 1.87 years and $11.7 \pm 11.7$ years, with bone age of $11.7 \pm$ 2.32 years and $10.1 \pm 10.02$ years, respectively. The relatively late initiation of treatment reflected the real-world situation. Multivariate linear regression model analysis showed that FAH is influenced positively by baseline height SDS in the boys and girls, whereas negatively by baseline bone age in girls, which was consistent with previous findings $[1,3,8,13,20]$. Many previous studies have demonstrated that the age when starting $\mathrm{GH}$ treatment is an important factor for its efficacy $[1,2,6,10,20]$. In this regard, our patients might have benefited more from $\mathrm{GH}$ therapy if the treatment had started earlier.

And we notice in this study, even in the control group, there is a spontaneous height gain of 1.16 SD. Economic factors need to be taken into account in the treatment of ISS. In China, growth hormone therapy for ISS is covered by families themselves. Whether to treatment or not, as well as the course of treatment, is decided by parents after weighing the family economic and height expectations.

This study had some limitations: Although it was a multi-center observation study, 344 of 475 cases entered the final analysis. It reflects "real-world" clinical practice and can be considered reliable, but which is not represented in random clinical trials. The sample is not big enough when stratification by treatment duration, if there is a larger sample in each subgroup, it will be better to validate our findings.

\section{Conclusions}

In summary, both girls and boys of ISS improved FAH by GH therapy even if treatments begin over 10 years old and majority of them reached TH. Some peripuberty ISS will have a spontaneous height gain. We recommend the course of $\mathrm{GH}$ treatment more than 2 years for girls, and longer courses for boys.

\section{Supplementary information}

Supplementary information accompanies this paper at https://doi.org/10. 1186/s12887-020-02034-8.

Additional file 1: Supp. Figure 1. $\triangle 1 \mathrm{HtSDS}$ (i.e., FAH SDS minus baseline height SDS) in each group.

Additional file 2: Supp. Figure 2. Comparisons of FAH SDS and TH SDS among girls in the pooled group with FAH SDS > 2 SD.

\section{Abbreviations}

ISS: Idiopathic short status; SD: Standard deviations; GH: Growth hormone; FAH: Final adult height; GnRHa: Gonadotropin-releasing hormone agonist; SDS: Standard deviation score; TH: Target height; HtSDS: Height standard deviation score; Cl: Confidence interval; RCTs: Randomized controlled Trials

\section{Acknowledgements}

The authors thank the patients, their families and the contributing physicians for their involvement in this study.

\section{Authors' contributions}

C.G. designed the investigation, data interpretation and revised the manuscript. D.W. performed most of the investigation, data analysis and wrote and revised the manuscript. R.C., S.C., G.L., L.C., Y.Y. and X.W. performed the investigation. Y.P. contributed to statistical analysis of data. All of the authors have read and approved the manuscript.

Funding

Not Applicable. 


\section{Availability of data and materials}

The datasets generated and analyzed during the present study are available from the corresponding author on reasonable request.

\section{Ethics approval and consent to participate}

This study was approved by the ethics committee of National Center for Children's Health \& Beijing Children's Hospital Affiliated to Capital Medical University. All procedures performed in studies involving human participants were in accordance with the ethical standards of the institutional and/or national research committee and with the 1964 Helsinki declaration and its later amendments or comparable ethical standards. All data published here are under the consent for publication. Written informed consent was obtained from all individual participants over 16 years old included in the study. A parent or guardian was on behalf of any participants under the age of 16 to write informed consent.

\section{Consent for publication}

Not Applicable.

\section{Competing interests}

The authors declare that they have no competing interests.

\section{Author details}

'Department of Endocrine and Genetics and Metabolism, Beijing Children's Hospital, Capital Medical University, National Centre for Children's Health, No. 56 Nanlishi Road, Xicheng District, Beijing 100045, China. ${ }^{2}$ Department of Endocrinology, Fuzhou Children's Hospital of Fujian Medical University Teaching Hospital, No.145, 817 Middle Road, Gulou District, Fuzhou, Fuzhou 350005, Fujian Province, China. ${ }^{3}$ Department of Pediatric, The second Affiliated Hospital of Guangxi Medical University, No.166, Daxuedong Road, Nanning, Guangxi, Nanning 530007, Guangxi, China. ${ }^{4}$ Department of Pediatric, Tianjin Medical University General Hospital, No.154, Anshan Road, Heping District, Tianjin 300052, Tianjin, China. ${ }^{5}$ Depatment of Endocrinology, Children's Hospital of Soochow University, No. 92, Zhongnan Street, Gongyeyuan District, Suzhou, Suzhou 215025, Jiangsu, China. ${ }^{6}$ Department of Endocrinology, Children's Hospital of Jiangxi Province, No.122, Yangming Road, Donghu District, Nanchang, Jiangxi, Nanchang 330006, Jiangxi, China. ${ }^{7}$ Department of Pediatric, Peking University Third Hospital, No.49, Huayuanbei Road, Haidian District, Beijing, Beijing 100191, Beijing, China. ${ }^{8}$ Center for Clinical Epidemiology and Evidence-Based Medicine, Beijing Children's Hospital, Capital Medical University, National Centre for Children's Health, No.56, Nanlishi Raod, Xicheng District, Beijing, Beijing 100045, Beijing, China.

Received: 23 July 2019 Accepted: 13 March 2020

Published online: 28 March 2020

\section{References}

1. Cohen P, Rogol AD, Deal CL, Saenger P, Reiter EO, Ross JL, Chernausek SD, Savage MO, Wit JM, On behalf of the 2007 ISS consensus workshop participants. Consensus statement on the diagnosis and treatment of children with idiopathic short stature: a summary of the growth hormone research society, the Lawson Wilkins pediatric Endocrine Society, and the European Society for Paediatric Endocrinology Workshop. J Clin Endocrinol Metab. 2008;93(11):4210-7.

2. Cohen LE. Idiopathic short stature: a clinical review. JAMA. 2014;311(17): 1787-96.

3. Sotos JF, Tokar NJ. Growth hormone significantly increases the adult height of children with idiopathic short stature: comparison of subgroups and benefit. Int J Pediatr Endocrinol. 2014;2014(1):15.

4. Collett-Solberg PF, Ambler G, Backeljauw PF, Bidlingmaier M, BMK B, MCS B, Cheung PT, CSY C, Cohen LE, Cohen P, Dauber A, Deal CL, Gong CX, Hasegawa Y, Hoffman AR, Hofman PL, Horikawa R, AAL J, Juul A, Kamenický P, Khadilkar V, Kopchick JJ, Kriström B, MLA L, Luo XP, Miller BS, Misra M, Netchine I, Radovick S, Ranke MB, Rogol AD, Rosenfeld RG, Saenger P, Wit JM, Woelfle J. Diagnosis, Genetics, and Therapy of Short Stature in Children: A Growth Hormone Research Society International Perspective. Horm Res Paediatr. 2019;92:1-14.

5. Collett-Solberg PF, Jorge AAL, Boguszewski MCS, Miller BS, Choong CSY, Cohen P, Hoffman AR, Luo XP, Radovick S, Saenger P. Growth hormone therapy in children; research and practice-a review. Growth Hormon IGF Res. 2019;29(44):20-32.

6. Rothenbuhler A, Linglart A, Bougneres P. A randomized pilot trial of growth hormone with anastrozole versus growth hormone alone, starting at the very end of puberty in adolescents with idiopathic short stature. Int J Pediatr Endocrinol. 2015:2015(1):4.

7. Kelnar CJ. Growth hormone for short children--whom should we be treating and why? J R Coll Physicians Edinb. 2012;42(1):32-3.

8. Deodati A, Cianfarani S. Impact of growth hormone therapy on adult height of children with idiopathic short stature: systematic review. BMJ. 2011;342: c7157.

9. Straetemans S, De Schepper J, Thomas M, Verlinde F, Rooman R. Bespeed. Validation of prediction models for near adult height in children with idiopathic growth hormone deficiency treated with growth hormone: a Belgian registry study. Horm Res Paediatr. 2016;86(3):161-8.

10. Wit JM, Rekers-Mombarg LT. Dutch growth hormone advisory G. final height gain by GH therapy in children with idiopathic short stature is dose dependent. J Clin Endocrinol Metab. 2002;87(2):604-11.

11. Li H, Ji CY, Zong XN, Zhang YQ. Height and weight standardized growth charts for Chinese children and adolescents aged 0 to 18 years. Zhonghua er ke za zhi. 2009;47(7):487-92.

12. Ross JL, Lee PA, Gut R, Germak J. Increased height standard deviation scores in response to growth hormone therapy to near-adult height in older children with delayed skeletal maturation: results from the ANSWER program. Int J Pediatr Endocrinol. 2015;2015(1):1.

13. Schena L, Meazza C, Pagani S, Paganelli V, Bozzola E, Tinelli C, et al. Efficacy of long-term growth hormone therapy in short non-growth hormonedeficient children. J Pediatr Endocrinol Metab. 2017;30(2):197-201.

14. Ross JL, Lee PA, Gut R, Germak J. Attaining genetic height potential: analysis of height outcomes from the ANSWER program in children treated with growth hormone over 5 years. Growth Horm IGF Res. 2015;25(6):286-93.

15. Rothenbuhler A, Ormieres B, Kalifa G, Bougneres P. A pilot study of growth hormone administration in boys with predicted adult short stature and near-ending growth. Growth Horm IGF Res. 2015;25(2):96-102.

16. Graham S, Weinman J, Auyeung V. Identifying potentially modifiable factors associated with treatment non-adherence in Paediatric growth hormone deficiency: a systematic review. Horm Res Paediatr. 2018;90(4):221-7.

17. Rapaport R, Lee P, Ross J, Saenger P, Ostrow V, Piccoli G. Growth hormone therapy in children born small for gestational age: results from the ANSWER program. Endocr Connect. 2018;7(10):1096-104.

18. Richmond E, Rogol AD. Treatment of growth hormone deficiency in children, adolescents and at the transitional age. Best Pract Res Clin Endocrinol Metab. 2016;30(6):749-55.

19. Pfäffle R, Land C, Schönau E, Holterhus PM, Ross JL, Oliveira CP, Child CJ, Benabbad I, Jia N, Jung H, Blum WF. Growth hormone treatment for short stature in the USA, Germany and France: 15 years of surveillance in the genetics and neuroendocrinology of short-stature international study (GeNeSIS). Horm Res Paediatr. 2018;90(3):169-80.

20. Wit JM, Clayton PE, Rogol AD, Savage MO, Saenger PH, Cohen P. Idiopathic short stature: definition, epidemiology, and diagnostic evaluation. Growth Hormo IGF Res. 2008;18(2):89-110.

\section{Publisher's Note}

Springer Nature remains neutral with regard to jurisdictional claims in published maps and institutional affiliations.

\section{Ready to submit your research? Choose BMC and benefit from:}

- fast, convenient online submission

- thorough peer review by experienced researchers in your field

- rapid publication on acceptance

- support for research data, including large and complex data types

- gold Open Access which fosters wider collaboration and increased citations

- maximum visibility for your research: over $100 \mathrm{M}$ website views per year

At $\mathrm{BMC}$, research is always in progress.

Learn more biomedcentral.com/submission 